\title{
Adaptation trade-offs
}

\section{Climate change adaptation initiatives need better planning to meet their targets.}

The 17 Sustainable Development Goals (SDGs), officially ratified in September 2015 by the United Nations, have (hopefully) initiated a new chapter of the international development agenda. Going beyond the Millennium Development Goals, the SDGs explicitly integrate the environmental and socio-economic dimensions of development and set priorities for all countries. Goal 13 states the need to take urgent action to combat climate change and its impacts, with particular emphasis on climate change adaptation in the form of strengthening resilience and adaptive capacity to climate hazards and natural disasters across the globe (http://go.nature.com/sNrU5E). Indeed, history tells us that the development of human societies rests on their ability to adapt to change - and global climate change is by far the biggest adaptation challenge of our time.

But development, whether exclusively socio-economic or sustainable, is an old issue. Governments and international agencies have been working on development for a long time. We have achieved significant progress in poverty alleviation, global health and environmental restoration and conservation. However, there is still a lot to be done. Despite the progress, in too many cases things have gone wrong and plenty of financial resources have been wasted. To some extent, climate change adaptation projects seem to be following the same path. The success of adaptation initiatives, like for any other development initiatives, rests on a combination of factors that is often hard to fully assess at the time of designing an intervention.

In a recent Commentary (Nature Clim. Change 5, 616-618; 2015), Benjamin Sovacool and colleagues looked at specific adaptation initiatives in both developing and developed countries, and illustrated the type of economic, social and political competing interests that emerge during their implementation. For example, the authors showed how the Mnazi Bay-Ruvuma Estuary Marine Park - a protected marine area in Tanzania, set up to bolster the climate change resilience of its coral reefs - limited the traditional fishing activities of local villagers, which lead to their dependence on energyintensive farming with higher rates of greenhouse gas emissions. This is a typical example of environmental-economic trade-offs that, if factored in at the time of designing the protected area, would have called for a parallel plan to develop sustainable economic activities in the affected villages.

Thinking along these lines is what social scientists refer to as a political economy approach. Political economy is the research field concerning struggle over power and resources, or the conditions by which some individuals, groups or institutions benefit from particular systems at the exclusion of others. Sovacool and co-workers created a political economy framework to help decision-makers identify the critical trade-offs of projects, and plan accordingly to avoid unintended consequences. The proposed framework has now been fully documented through the in-depth analysis of four new case studies by Sovacool and Linnér in their forthcoming book, The Political Economy of Climate Change Adaptation (http://go.nature.com/QjCMMU). Not only will the book inform climate adaptation researchers and practitioners, it will hopefully also inspire development experts.

\section{Emissions scandal response}

\section{Revelations around diesel vehicle emissions hint at a more robust environmental regulation regime.}

The dust is still settling on the revelation that millions of diesel vehicles have been circumventing emissions regulations. The scandal highlights the difficulties of enforcing effective regulation to protect a common good: the atmosphere. It also hints at future tensions that could arise between those tasked with protecting the planet and the industries that damage it.

On the face of it, Volkswagen's activity would seem to be the epitome of a 'green crime'. But things aren't so simple. There is a fine line between an offence and a crime, as Angus Nurse, Senior Lecturer in Criminology at the University of Middlesex, explains. The tension between these two concepts is likely to increase as policymakers seek ways to reduce greenhouse gas emissions across the board.
Politicians could decide to legislate against the emission of greenhouse gases beyond a certain level, thereby criminalizing corporations and industries that fail to comply. But that would be a bold move, Nurse says. Politicians don't like sending corporations to jail. They would much rather settle out of court, as they have in the past in cases such as the Deepwater Horizon oil spill, of which BP is still feeling the financial effects.

That implies continuing to regulate. But, as the diesel emissions scandal shows, there must be effective enforcement, and a large enough punishment, for such regulations to stimulate compliance.

Public pressure can aid this. It helps if a charismatic species is involved. Regulators across the world are looking at revising laws on the hunting and import of trophy animals in response to the killing of Cecil the lion by Walter Palmer.

So is Volkswagen the charismatic species of emissions regulation? There are similarities between the cases. In both, the victims and perpetrators seem relatively clear cut. And there is likely to be a similar fall-out, with tightened regulation and greater scrutiny of the respective industries. But there are also wider lessons for environmental policymakers, including those tasked with tackling climate change.

The emissions scandal shows how an environmental harm can go from being hidden to a public offence. Industries must be wondering how long it will be until regulators decide such activities are not just offensive, but criminal. 